\title{
PENGARUH KOMPENSASI DAN KEPUASAN KERJA TERHADAP TURNOVER INTENTION PADA PIZZA HUT PALU
}

\author{
Rahmat \\ Bakri Hasanuddin \\ Andi Indriani Ibrahim \\ Jurusan Manajemen S1, Fakultas Ekonomi Dan Bisnis, Universitas Tadulako \\ Email: rahmatamrin@gmail.com
}

\begin{abstract}
The Purpose of this study was to analyze and determine the effect of compensation and job satification variables toward the employee turnover intention on Pizza Hut Palu. Sample size used in this study were 53 respondents, the entire population used as respondents (census). The data analysis method used was multiple inearregression used for windows relation 25.0. The results of this study indicate that the compensation and job satisfaction variables of Pizza Hut Palu employee turnover demands, the compensation variable partially has a significant relationship to the Pizza Hut Palu employee turnover intention variable and the job satisfaction variable is significantly significant to the Pizza Hut Palu employee turnover intention.
\end{abstract}

Keywords: Compensation, Job Satification, Turnover Intention

Abstrak

Tujuan dari penelitian ini adalah untuk menganalisis dan menentukan pengaruh variabel kompensasi dan kepuasan kerja terhadap intensi turnover karyawan pada Pizza Hut Palu. Ukuran sampel yang digunakan dalam penelitian ini adalah 53 responden, seluruh populasi dijadikan responden (sensus). Metode analisis data yang digunakan adalah regresi berganda yang digunakan untuk hubungan Windows 25.0. Hasil dari penelitian ini menunjukkan bahwa variabel kompensasi dan kepuasan kerja secara serempak berpengaruh terhadap turnover intention karyawan Pizza Hut Palu, variabel kompensasi secara parsial memiliki pengaruh yang signifikan terhadap variabel turnover intention karyawan Pizza Hut Palu dan variabel kepuasan kerja secara parsial berpengaruh signifikan terhadap turnover intention karyawan Pizza Hut Palu.

Kata kunci: Kompensasi, Satifikasi Pekerjaan, Intensi Turnover

\section{PENDAHULUAN}

Di era globalisasi pada saat ini perusahaan dituntut untuk dapat bersaing dengan ketat agar dapat bertahan pada bisnis saat ini. Perusahaan memiliki kinerja yang baik adalah perusahaan yang memiliki keunggulan kompetitif dalam bersaing. Untuk bisa unggul dalam bersaing perusahaan harus mempunyai cara yang terbaik dalam meningkatkan kinerja perusahaan. Strategi perusahaan yang banyak digunakan saat ini adalah optimalisasi penggunaan sumber daya yang terdapat pada perusahaan tersebut.

Sumber daya manusia adalah aset penting bagi perusahaan, sebab perusahaan membutuhkan sumber daya manusia sebagai penggerak aktivitas dalam sebuah perusahaan. Dalam industri dan organisasi manusia merupakan sumber daya yang penting, untuk mencakup tenaga kerja yang bermutu serta mempertahankan kualitas dan mengendalikan biaya ketenagakerjaan (Cascio,1987).

Perusahaan perlu memberikan kontribusi kepada karyawan dengan cara mensejahterakan karyawan. Karyawan biasa meninggalkan pekerjaan mereka (turnover) jika kebutuhan karyawan tidak terpuaskan dan tidak mendapat perhatian yang pantas dari perusahaan, bagi perusahaan karyawan memiliki peran yang sangat penting. Keluarnya karyawanditandai dengan adanya keinginan karyawan untuk berpindah pekerjaan. Bagi perusahaan tingginya tingkat turnover sudah menjadi masalah yang 
serius, hal ini dikarenakan adanya suatu sistem rekrutmen yang sudah tercapai menyeleksi karyawan berkualitas yang akhirnya mengecewakan perusahaan sebab karyawan yang sudah direkrut memutuskan untuk bekerja pada perusahaan yang lain (Toly, 2001). Tingginya turnover di perusahaan dapat mengeluarkan biaya pelatihan yang sudah dikeluarkan untuk karyawan, biaya rekrutmen dan pelatihan kembali (Suwandi dan Indriantoro, 1999). Keinginan seseorang untuk keluar dari organisasi salah satunya dikarenakan kurangnya kepuasan kerja karyawan.

Pizza Hut merupakan restoran waralaba yang memiliki koneksi restoran pizza terbesar di dunia yang hampir 12.000 cabang restoran yang tersebar di 84 negara. Pizza Hut memiliki 213 cabang yang tersebar di seluruh Indonesia termasuk berada di kota Palu yang bediri pada tahun 2012. Pizza Hut menghidangkan berbagai jenis pizza dengan berbagai macam topping yang berbeda selain tersedianya pizza. Pizza Hut pun menghidangkan beraneka macam makanan dan minuman seperti salad, pasta, nasi, sup, dan sebagainya. Pizza Hut populer dengan sebutan "Si Atap Merah" dan menjadi simbol dalam pelayanan jasa restoran terbaik (http://id.wikipedia.org, diakses 8 September 2017). Walaupun mempunyai nama yang cukup besar pada kenyataannya tidak ada jaminan untuk karyawan tetap bertahan di dalamnya. Hal itu dapat diindikasikan bahwa terdapat faktor penyebab karyawan keluar.

\section{KAJIAN LITERATUR DAN PENGEMBANGAN HIPOTESIS}

\section{Pengertian Kompensasi}

Hasibuan (2005: 118) mengemukakan pengertian kompensasi yaitu semua bentuk pendapatan baik berbentuk uang, barang secara langsung ataupun tidak langsung yang diberikan kepada pegawai sebagai imbalan bagi karyawan atas semua kerja kerasnya untuk perusahaan. Handoko (1998: 155), kompensasi merupakan semua hal yang didapatkan oleh pegawai sebagai bagian dari balas jasa untuk apa yang telah dikerjakannya. Rivai (2009: 741) Kompensasi ialah suatu yang didapatkan pegawai sebagai balasan atas kontribusinya sebagai karyawan untuk perusahaan.

\section{Komponen-Komponen Kompensasi}

Rivai (2009:744) komponen kompensasi antara lain sebagai berikut:

1. Gaji

Gaji merupakan balasan dari perusahaan yang berbentuk finansial yang diberikan kepada pegawai sebagai konsekuensi pada kedudukannya sebagai pegawai apabila pegawai memberikan kontribusi pikiran dan tenaga untuk mencapai tujuan dari perusahaan. Atau sebagai bayaran yang tetap yang didapatkan oleh karyawanatas kontribusi keanggotaannya pada perusahaan/organisasi.

2. Upah

Upah adalah imbalan yan berbentuk financial yang langsung diberikan pada karyawan yang sesuai dengan jam kerja, jumlah barang yang didapatkan atau besarnya layanan yang diberikan. Jadi berbeda dengan gaji yang jumlahnya relative tetap, besarnya pemberian upah dapat berubah tergantung dari hasil yang di keluarkan.

\section{Insentif}

Insentif adalah upah (finansial) yang langsung diberikan kepada pegawai atas kerja kerasnya yang dinilai melampaui standar yang telah ditetapkan.Insentif ialah upah langsung yang diberikan di luar pengupahan dan penggajian merupakan kompensasi yang tetap, dan biasa disebut sebagai bonus gaji sesuai dengan kinerja (pay for performance plan).

4. Kompensasi Tidak Langsung (fringe benefit)

Fringe benefit adalah upah tambahan dan diberikan berdasar pada kebijakan perusahaan bagi seluruh karyawannya dalam upaya mensejahterakan para karyawan. Misalnya, berupa fasilitas, tunjangan, asuransi, dana pensiun, dan lain-lain. 


\section{Pengertian Kepuasan Kerja}

Robbins (1996) mengemukakan pengertian kepuasan kerja sebagai sikap perusahaan atas kinerja karyawannya. Selisih antara besar nilai kompensasi yang diterima oleh karyawan dengan kontribusi produktivitas mereka terhadap perusahaan. Menurut Handoko (2001) kepuasan kerja merupakan kondisi emosional karyawan dalam menyikapi pekerjaan dan kompensasi yang didapatkannya. Kepuasan kerja dapat pula diartikan sebagai rasa senang karyawan yang berhubungan dengan pekerjaan yang dilakukannya Wether\& Davis (1996).

\section{Indikator Kepuasan Kerja}

Indikator yang digunakan dalam penelitian ini mengukur kepuasan kerja berpacu pada penelitian Judge dan Locke (1993) yaitu :

\section{Pekerjaan Itu Sendiri (Workitself)}

Pada penelitian Judge dan Locke (1993) dijelaskan apabila seorang karyawan pada sebuah organisasi/perusahaan memiliki otonom yang cukup tinggi, kebebasan dalam penentuan tugas dan jadwal kerja mereka sendiri, perubahan pada variabel memberikan pengaruh relatif besar terhadap kepuasan kerja. Robbins (2008) mengemukakan apabila karyawan cenderung untuk lebih menyukai pekerjaan yang memberikan mereka kesempatan dalam mengembangkan keterampilan dan kemampuan karyawan dan menawarkan berbagai rmacam tugas, kebebasan dan umpan balik mengenai seberapa baik mereka menyelesaikan pekerjaan sehingga dapat tercipta kesenangan dan kepuasan karyawan.

\section{Supervisi}

Gibson, et al (1995) menyatakan bahwa gaya kepemimpinan yang bisa diterapkan dengan tepat yang akan memuaskan bawahannya. Hal tersebut terlihat dari sikap bawahan yang cenderung patuh dengan atasan, dan mempunyai semangat kerja yang tinggi.

3. Hubungan dengan teman sekerja (Co-workers)

Dalam hal ini faktor penting dalam menciptakan kepuasan kerja karena manusia adalah makhluk sosial yang butuh akan interaksi dengan orang lain. Tidak ada seorang yang dapat mengandalkan kemampuannya sendiri, karena setiap individu mempunyai batas kemampuan masing-masing. Dengan begitu akan menciptakan hubungan yang baik sesama rekan kerja, rasa aman dan nyaman dalam bekerja bisa tercapai.

\section{Kesempatan promosi (Promotion opportunities)}

Promosi dapat meningkatkan status sosial individu menjadi lebih tinggi, pertumbuhan pribadi, dan tanggung jawab yang akan lebih banyak. Dengan demikian setiap individu karyawan yang mempresepsikan bahwa keputusan promosi dibuat secara adil, memiliki kemungkinan lebih besar mengalami kepuasan kerja (Robbins,2008).

\section{Pengertian Turnover Intention}

Harnoto (2002: 2) mengemukakan bahwa Turnover Intention ialah ketentuan dan kemauan seseorang untuk dapat keluar dari perusahaan. Menurut Witasari (2009) Turnover Intention ialah keseriusan ataupun keinginan seseorang sehingga tidak lagi bekerja pada perusahaan. Penjelasan lain dikemukakan oleh Harninda dalam Wendi (2009:5), turnover intention pada dasarnya sama dengan keinginan berpindahnya karyawan pada satu tempat kerja ke tempat kerja lainnya.

\section{Indikator Turnover Intention}

Menurut Mobley et al (1978) indikator untuk mengukur turnover intention terdiri atas:

1. Memikirkan untuk Keluar (Thinking of Quitting): 
Mencerminkan seorang untuk berpikir keluar dari pekerjaan atau tetap berada di dalam lingkungan pekerjaan. Di awali dari ketidakpuasan kerja yang dirasakan karyawan, selanjutnya karyawan akan mulai berpikiran untuk keluar dari tempatnya bekerja.

2. Pencarian Alternatif Pekerjaan (Intention to search for alternatives):

Mencerminkan seorang yang mempunyai keinginan dalam mencari pekerjaan di perusahaan lain. Apabila karyawan akan berpikir untuk keluar pada pekerjaannya, karyawan tersebut akan mencari pekerjaan yang lebih baik.

3. Niat untuk keluar (Intention to quit):

Mencerminkan seseorang untuk mempunyai niat untuk keluar dari perusahaan. Karyawan yang mempunyai niat untuk keluar bila sudah memperoleh pekerjaan yang lebih baik dan akan diakhiri keputusan karyawan tetap tinggal atau keluar dari pekerjaan.

\section{Pengaruh Antar Variabel Penelitian}

\section{Pengaruh Kompensasi terhadap Turnover Intention}

Untuk memotivasi karyawan dalam meningkatkan kinerja perusahaan perlu memberikan kompensasi yang baik. Perusahaan akan diapresiasi oleh karyawan bila pemberian kompensasi sesuai, karyawan akan termotivasi dalam bekerja karyawan dan juga akan cenderung setia pada perusahaan.

Pengaruh kompensasi dan turnover intention memiliki suatu pengaruh yang negatif variabel kompensasi dan turnover intention hal ini sejalan pada penelitian yang sudah dilakukan oleh widayanti \& Yolanda (2016). Semangat kerja karyawan akan menurun apabila kompensasi yang diberikan buruk. Situasi tersebut diakibatkan perusahaan tidak memberikan penghargaan yang sesuai dengan kinerja karyawan. Pemberian penghargaan yang tidak sebanding dengan apa yang dikerjakan membuat semangat pekerja menurun. Apabila tidak sesuai harapan karyawan hal itu mengakibatkan turnover intention menjadi tinggi sehingga karyawan keluar dari perusahaan.

\section{Pengaruh Kepuasan Kerja terhadap Turnover Intention}

Pekerja akan merasakan puas dengan yang mereka kerjakan dapat menimbulkan dampak positif untuk perusahaan sebab semangat dalam bekerja akan tumbuh dari kepuasan karyawan tersebut. Keinginan seseorang keluar dari perusahaan diduga adanya ketidakpuasan karyawan.Ketidakpuasan kerja telah sering dan dapat diidentifikasi sebagai suatu alasan yang penting dan dapat menyebabkan individu meninggalkan pekerjaannya.

Kepuasan kerja juga dihubungkan secara negatif dengan keluarnya (turnover) karyawan. Penelitian yang dilakukan oleh Abdurrahim dan Hastin Umi Anisah (2015) mengenai pengaruh kepuasan kerja terhadap turnoverintention mempunyai pengaruh yang negatif. Mereka yang kepuasan kerjanya lebih rendah mudah untuk meninggalkan perusahaan dan mencari kesempatan di perusahaan lain. Pemikiran seseorang untuk keluar biasa dipengaruhi oleh kepuasan kerja. Penilaian terhadap berbagai alternatif pekerjaan lain, akibatnya akan membuat turnoverkaryawan karena seseorang yang memilih keluar dari organisasi akan menginginkan hasil yang lebih memadai di temat lain (Andini, 2006).

\section{METODE PENELITIAN}

\section{Jenis Penelitian}

Metode atau pendekatanyang dipakai pada penelitian ini menggunakan dasar penelitian asosiatif. Penelitian asosiatif ini paling sedikit terdapat dua variabel yang dapat dihubungkan. Jadi penelitian asosiatif adalah penelitian yang meneliti tentang hubungan antara dua variabel atau lebih (Sugiyono, 2010: 55).

\section{Lokasi Penelitian}

Penelitian ini dilakukan langsung di alamat usaha perusahaan Pizza Hut palu di jalan Emy Saelan No 17 Palu. Alasan penelitian dilakukan di Pizza Hut Palu karena peneliti melihat adanya fenomena yang terkait dengan variabel penelitian serta peneliti ingin mengetahui seberapa besarkah pengaruh kompensasi dan kepuasan kerja terhadap turnover intention karyawan yang terdapat di Pizza Hut Palu.

\section{Populasi dan Teknik Penarikan Sampel}


Populasi yang diambil dalam penelitian ini yaitu semua pegawai Pizza Hut yaitu sebanyak 53 orang. Melihat keterbatasan jumlah populasi, maka penulis menetapkan populasi penelitian sebagai sampel dalam penelitian yang ditentukan dengan memakai teknik sampel jenuh (sensus) yaitu mengambil sampel yang dimana semua populasi digolongkan menjadi sampel penelitian (Sugiyono, 2012:91).

\section{Uji Validitas}

Sebuah instrumen dikatakan valid apabila memiliki koefisien korelasi (corrected item total correlation $) \geq 0,3$, sebaliknya bila koefisien korelasi $\leq 0,3$ maka dikatakan tidak valid.

\section{Uji Reliabilitas}

Jika variabel dinyatakan reliabel apabila memiliki nilai $(\alpha)>0,60$ atau sebaliknya (Ghozali, 2005).

\section{Uji Normalitas}

Bertujuan untuk mengetahui uji t dan F mengikuti pada distribusi normal serta menguji variabel pengganggu memberikan distribusi yang normal. apabila asumsi ini dilanggar maka uji statistik jadi tidak valid untuk beberapa sampel kecil.

Cara melihat normalitas residual adalah dengan membandingkan hasil distribusi kumulatif serta melihat normal probability plot jika terjadi distribusi kumulatif dari distribusi normal. Distribusi yang normal akan berbentuk suatu pola pada garis lurus diagonal, dan plotting dari data residual bisa dibandingkan dengan garis diagonal. Apabila distribusi residual normal, garis yang digambarkan pada data yang sebenarnya akan mengikuti garis diagonal (Sugiyono, 2013:229).

\section{Uji Multikolinieritas}

Digunakan agar dapat mengetahui apakah model regresi telah ditemukan korelasi yang kuat antar variabel bebas. Apabila terjadi hubungan kuat, maka ada masalah pada multikolinearitas yang mesti diolah kembali. Apabila tidak terjadi korelasi diantara variabel independen maka model regresinya baik.

\section{Uji Heteroskedastisitas}

Uji heterokedastisitas pada pengujian ini pada model regresi apakah terjadi ketidaksamaan varian dari residual dari pengamatan satu ke pengamatan lain. Apabila varian dari residu itu tetap maka disebut homokedastisitas. Model regresi dapat dikatakan baik jika tidak terjadi heterokedastisitas.

\section{Analisis Regresi Linear Berganda}

Metode analisis yang digunakan dalam penelitian ini ialah menggunakan alat analisis statistik regresi linear berganda (Multiple Linear Regression). Di penelitian ini memakai bantuan komputer SPSS. Yaitu model umum yang bentuk persamaan alat analisis statistik parametrik regresi linear berganda (Rangkuti 2006:165) dapat digambarkan sebagai berikut:

$$
\mathrm{Y}=\mathrm{a}+\mathrm{b}_{1} \mathrm{X}_{1}+\mathrm{b}_{2} \mathrm{X}_{2}+\ldots . .+\mathrm{bnXn}+\mathrm{e}
$$

Bila formulasi regresi linear berganda tersebut diaplikasikan dalam penelitian ini, maka diperoleh bentuk persamaan sebagai berikut:

$$
\mathrm{Y}=\mathrm{a}+\mathrm{b}_{1} \mathrm{X}_{1}+\mathrm{b}_{2} \mathrm{X}_{2}+\mathrm{e}
$$

Dimana:

$$
\begin{array}{ll}
\mathrm{Y} & =\text { Turnover Intention } \\
\mathrm{X}_{1} & =\text { Kompensasi } \\
\mathrm{X}_{2} & =\text { Kepuasan Kerja }
\end{array}
$$


a $\quad=$ Konstanta

$\mathrm{b}_{1} \ldots \mathrm{b}_{2}=$ Nilai Koefisien Regresi

$\mathrm{e} \quad=$ Error

\section{Uji Hipotesis}

\section{Uji F atau uji serempak}

Pada penelitian ini, uji F dipakai agar dapat mengetahui tingkat signifikansi pengaruh variabel bebas secara bersama-sama (simultan) terhadap variabel terikat (Ghozali, 2006:84). Hipotesis yang digunakan dalam pengujian ini adalah:

1. Apabila signifikansi F>0,05, maka variabel-variabel bebas yaitu Kompensasi dan Kepuasan Kerja tidak berpengaruh secara signifikansi secara bersama-sama terhadap variabel terikatnya yaitu Turnover Intention Karyawan.

2. Apabila signifikansi $\mathrm{F}<0,05$, maka variabel-variabel bebas yaitu Kompensasi dan Kepuasan Kerja berpengaruh secara signifikan secara bersama-sama terhadap variabel terikatnya yaitu Turnover Intention Karyawan.

\section{Uji t atau Uji parsial}

Uji t digunakan menguji tingkat signifikansi antara hubungan variabel $\mathrm{X}$ dan $\mathrm{Y}$, apakah variabel X1 dan X2 benar-benar mempunyai pengaruh terhadap variabel Y secara terpisah atau parsial (Ghozali, 2006:84). Hipotesis yang dipakai di pengujian ini adalah:

1. Apabila signifikansi $t>0,05$, maka variabel independen (Kompensasi dan Kepuasan Kerja) tidak berpengaruh signifikan terhadap variabel dependen (Turnover Intention Karyawan).

2. Apabila signifikansi $t<0,05$, maka variabel independen (Kompensasi dan Kepuasan Kerja) berpengaruh signifikansi terhadap variabel dependen (Turnover Intention Karyawan).

\section{Uji $\mathbf{R}^{2}$ atau Uji Determinasi}

Koefisien determinasi digunakan sehingga bisa melihat sseberapa jauh kemampuan dari model regresi bila menerangkan variasi variabel terikat. Nilai adjusted $R^{2}$ memiliki range antara nol hingga satu. Nilai adjusted $R^{2}$ yang makin mendekati angka nol berarti kemampuan dari variabel bebas dalam menjelaskan variasi variabel dependen makin terbatas. Sementara apabila nilai adjusted $R^{2}$ nya makin mendekati satu berarti variabel bebas menyediakan informasi yang dibutuhkan agar bisa memprediksi variasi variabel dependen (Ghozali, 2006:83).

\section{PEMBAHASAN HASIL PENELITIAN}

\section{Hasil Analisis Regresi Linier Berganda}

Analisis regresi linier berganda digunakan untuk mengetahui seberapa besar pengaruh variabel bebas (X) yang terdiri dari Kompensasi (X1) dan Kepuasan Kerja (X2) terhadap variabel terikat (Y) yaitu Turnover Intention. Nilai koefisien regresi linier berganda dapat dilihat pada Tabel 5.9 berikut: 


\section{Tabel 1 Rekapitulasi Hasil Uji Regresi}

\begin{tabular}{|c|c|c|c|c|c|c|}
\hline \multirow{2}{*}{\multicolumn{2}{|c|}{ Model }} & \multicolumn{2}{|c|}{$\begin{array}{l}\text { Unstandardized } \\
\text { Coefficients }\end{array}$} & \multirow{2}{*}{$\begin{array}{l}\text { Standardized } \\
\text { Coefficients } \\
\text { Beta }\end{array}$} & \multirow[t]{2}{*}{$\mathrm{T}$} & \multirow{2}{*}{ Sig } \\
\hline & & B & Std. Error & & & \\
\hline & (Constant) & 48.880 & 7.803 & & 6.264 & .000 \\
\hline 1 & Kompensasi & -.259 & .094 & -.331 & -2.761 & .008 \\
\hline 2 & Kepuasan Kerja & -.343 & .102 & -.405 & -3.374 & .001 \\
\hline \multicolumn{3}{|c|}{ R Square $\left(R^{2}\right)$} & $=0.281$ & F-Hitung & & $=9.747$ \\
\hline \multicolumn{3}{|c|}{ Adjusted R Square } & $=0.252$ & Konstanta & & $=48.880$ \\
\hline \multicolumn{3}{|c|}{ Multiple R } & $=0.530$ & Sig.F & & $=0.000$ \\
\hline
\end{tabular}

Sumber:hasil pengolahan data kuesioner

Hasil analisis regresi linear berganda dalam Tabel 1 diatas, kemudian dimasukkan kedalam model persamaan regresi linear berganda berikut:

$$
\mathrm{Y}=48,880-0,259 \mathrm{X}_{1}-0,343 \mathrm{X}_{2}
$$

a. Nilai konstanta a adalah 48,880 yang menyatakan bahwa variabel kompensasi dan kepuasan kerja $\left(\mathrm{X}_{1}\right.$ dan $\mathrm{X}_{2}$ ) bernilai 0 maka variabel dependen turnover intention $(\mathrm{Y})$ bernilai sebesar 48.880 .

b. Nilai koefisien regresi $b_{1}$ adalah $-0,259$ yang menunjukkan bahwa variabel kompensasi $\left(X_{1}\right)$ berpengaruh negatif terhadap turnover intention. Berarti apabila kompensasi meningkat maka turnover intention akan menurun.

c. Nilai koefisien regresi $b_{2}$ adalah $-0,343$ yang menunjukkan bahwa variabel kepuasan kerja $\left(X_{2}\right)$ berpengaruh negatif terhadap turnover intention. Hal ini menunjukan apabila kepuasan kerja meningkat maka turnover intention karyawan akan mengalami penurunan.

\section{Pengujian Hipotesis Pertama (Uji F)}

Diketahui $\mathrm{F}_{\text {hitung }}$ sebesar 9,747 dengan nilai signifikan 0,000 dengan nilai $\alpha$ (batas signifikan) adalah 0,05 . Sehingga bisa diketahui bahwa $0,000<0,05$ maka model analisis regresi ini dinyatakan signifikan. Dengan demikian (Ho) ditolak dan (Ha) diterima, karena terdapat pengaruh antara variabel independen (kompensasi dan kepuasan kerja) secara simultan terhadap variabel dependen (turnover intention).

\section{Uji Signifikansi Pengaruh Parsial (Uji t)}

1. Variabel kompensasi (X1), nilai signifikansinya sebesar 0,008. Karena angka probabilitas signifikansi < 0,05 maka Ho ditolak dan Ha diterima, dengan demikian kompensasi berpengaruh signifikan terhadapturnover intention karyawan. 
2. Variabel kepuasan kerja (X2), nilai signifikansinya sebesar 0,001. Karena angka probabilitas signifikansi < 0,05 maka Ho ditolak dan Ha diterima, dengan demikian kepuasan kerja berpengaruh signifikan terhadap turnover intention karyawan.

\section{Hasil Uji Koefisien Determinasi $\left(\mathbf{R}^{2}\right)$}

Dari hasil pengolahan data yang dilakukan dengan menggunakan aplikasi komputer (software) program IBM SPSS Statistics 25, dapat dilihat bahwa nilai R dan R Square masing - masing 0,530 dan 0,281 dijelaskan sebagai berikut:

1. Koefisien korelasi (R) memiliki nilai sebesar 0,530 yang artinya bahwa variabel yang diteliti yaitu kompensasi dan kepuasan kerja mempunyai hubungan yang kuat dengan variabel terkaitnya sebesar 0,530 atau sebesar 53\%.

2. Nilai R Square atau koefisien determinasi memiliki nilai sebesar 0,281 artinya pengaruh kompensasi dan kepuasan kerja terhadap turnover intention karyawan pizza hut Palu adalah sebesar $28,1 \%$, sedangkan $71,9 \%$ dipengaruhi oleh faktor lain yang dapat mempengaruhi turnover intention yang tidak dimasukkan dalam penelitian ini.

\section{PENUTUP}

\section{Kesimpulan}

Berdasarkan hasil dan pembahasan penelitian, maka berikut beberapa kesimpulan yang menyangkut penelitian ini:

1. Variabel kompensasi dan kepuasan kerja secara seerempak berpengaruh terhadap turnover intention karyawan Pizza Hut Palu.

2. Variabel kompensasi secara parsial berpengaruh signifikan (negatif) terhadap turnover intention karyawan Pizza Hut Palu.

3. Variabel kepuasan kerja secara parsial berpengaruh signifikan (negatif) terhadap turnover intention karyawan Pizza Hut Palu.

\section{Saran}

Berdasarkan kesimpulan yang dapat ditarik dari uraian dan pembahasan pada bab-bab sebelumnya maka penulis memberikan saran yang mungkin bermanfaat untuk menurunkan turnover intention karyawan:

1. Disarankan kepada perusahaan Pizza Hut Palu agar meningkatkan variabel kompensasi pada dimensi gajiuntuk indikator (gaji tidak tepat waktu) yang lebih di perhatikan karena memiliki kontribusi tertinggi. Dalam hal ini perusahaan perlu memperhatikan gaji para karyawannya agar dibayarkan tepat waktu.

2. Disarankan kepada perusahaan Pizza Hut Palu agar meningkatkan variabel kompensasi pada dimensi upahuntuk indikator (upah tidak sesuai lama kerja) yang lebih di perhatikan karena memiliki kontribusi tertinggi. Dalam hal ini perusahaan perlu memperhatikan pemberian upah yang sesuai dengan lama kerja karyawan sehingga karyawan merasa puas atas pekerjaan yang mereka lakukan.

3. Disarankan kepada perusahaan Pizza Hut Palu agar meningkatkan variabel kepuasan kerja pada dimensi pekerjaan itu sendiriuntuk indikator (tidak mendapat hasil yang terbaik) yang lebih di perhatikan karena memiliki kontribusi tertinggi. Dalam hal ini pimpinan perlu memberikan arahan dan pelatihan ataupun merotasi pekerjaan karyawan sehingga dapat memaksimalkan kinerja karyawan.

4. Disarankan kepada perusahaan Pizza Hut Palu agar meningkatkan variabel kepuasan kerja pada dimensi pekerjaan itu sendiriuntuk indikator (tidak mendapat hasil yang terbaik) yang lebih di 
perhatikan karena memiliki kontribusi tertinggi. Dalam hal ini pimpinan perlu memberikan arahan dan pelatihan ataupun merotasi pekerjaan karyawan sehingga dapat memaksimalkan kinerja karyawan.

5. Disarankan kepada perusahaan Pizza Hut Palu agar menurunkan variabel turnover intention pada dimensi memikirkan alternatif pekerjaan untuk indikator (mendapatkan pekerjaan baru) yang lebih di perhatikan karena memiliki kontribusi tertinggi. Dalam hal ini karyawan akan memikirkan alternatif pekerjaan lain bila perusahaan saat ini tidak memberikan gaji yang sesuai dengan keinginan karyawan.

6. Disarankan untuk penelitian selanjutnya, diharapkan dapat menambah variabel penelitian yang dapat mempengaruhi turnover intention pada Pizza Hut Palu, agar hasil penelitiannya dapat memberikan kontribusi yang lebih untuk pihak - pihak yang bersangkutan dalam penelitian ini.

\section{REFERENSI}

Arep, Ishak \& Hendri Tanjung. 2002. Manajemen Motivasi. Jakarta: UniversitasTrisakti.

Ghozali, Imam. 2006. Aplikasi Analisis Multivariate dengan Program SPSS (Edisi Ke 4). Semarang: Badan Penerbit Universitas Diponegoro.

Handoko, Hani. 2001. Manajemen Personalisa dan Sumber Daya Manusia. Yogyakarta: BPFE.

Hasibuan, Malayu. 2012. Manajemen Sumber Daya Manusia. Edisi Revisi.Cetakan keenam belas. Jakarta: PT Bumi Aksara.

Judge, T.A., and Locke, E.A. 1993. Effect of Dysfunctional Thought Processes on Subjective WellBeing and Job Satisfaction. Journal of Applied Psychology. 78 (3): 475-490.

Rivai, V. \& Jauvani, S. E. 2009. Manajemen Sumber Daya Untuk Perusahaan. Jakarta: PT. Rajagrafindo Persada.

Robbins, Stephen P \& Timothy Judge. 2008. Perilaku Organisasi. Edisi 12. Buku 1. Jakarta: Salemba Empat.

Sugiyono 2013. Metode Penelitian Manajemen. Cetakan ke-1, Alfabeta, Bandung.

Suwandi dan Nur Indriantoro. 1999. Pengujian Model Turnover Pasewark danStrawser: Studi Empiris pada Lingkungan Akuntansi Publik.Jurnal Riset Akuntansi Indonesia.No. 2, halaman 173-195. 